\title{
What respiratory targets should be recommended in patients with brain injury and respiratory failure?
}

Shirin K. Frisvold', Chiara Robba ${ }^{2}$ and Claude Guérin $3,4,5,6,7^{*}$ (1)

๑ 2019 Springer-Verlag GmbH Germany, part of Springer Nature

\section{Introduction}

Acute brain injury (ABI) as a consequence of hypoxia, trauma, or stroke is a major cause of disability and death. Mechanical ventilation (MV) affects cerebral hemodynamics viadifferent mechanisms. First, it can optimize the blood level of oxygen and the arterial partial pressure of carbon dioxide $\left(\mathrm{PaCO}_{2}\right)$, which is a potent modulator of intracranial pressure (ICP) owing to its effect on cerebrovascular tone and consequently cerebral perfusion pressure. Hypercapnia mainly triggers vasodilatation and increases ICP whereas hypocapnia causes vasoconstriction. Second, increased intrathoracic pressure caused by application of positive end-expiratory pressure (PEEP) may impair venous return, thus reducing mean arterial pressure and/or increasing ICP. Consequently, in ABI patients, it has become traditional to target a combination of high tidal volume $(\mathrm{Vt})(>9 \mathrm{ml} / \mathrm{kg})$ and low PEEP [1]. Concurrent acute respiratory failure or acute respiratory distress syndrome (ARDS) in ABI is multifactorial, its causes including aspiration, chest trauma, $\mathrm{ABI}$-induced lung inflammation with reduced pulmonary compliance, and ventilator-induced lung injury (VILI), and it is associated with a worse outcome [2]. VILI is a modifiable risk factor, amenable to the use of lung protective ventilation (LPV), an approach that includes the application of low Vt and high PEEP levels [3]. Clearly, therefore, in cases where $A B I$ and respiratory failure coexist, it is necessary to determine which is the optimal ventilator strategy. The aim of this editorial is to review

\footnotetext{
*Correspondence: claude.querin@chu-lyon.fr

${ }^{3}$ Service de Médecine Intensive-Réanimation, Hospices Civils de Lyon, Lyon, France

Full author information is available at the end of the article
}

briefly the current evidence on the use of ventilator settings to achieve respiratory targets (including oxygen and $\mathrm{PaCO}_{2}$ levels) in patients with $\mathrm{ABI}$ and acute respiratory failure or ARDS.

\section{Oxygen and carbon dioxide targets}

The oxygen and $\mathrm{PaCO}_{2}$ targets applied in $\mathrm{ABI}$ are different from the levels targeted in patients with ARDS. In the latter group, modest oxygenation targets and permissive hypercapnia are accepted as consequences of the MV settings required by LPV strategies [3] (Fig. 1). By contrast, in ABI, hypoxia must be avoided, or promptly treated, as it can cause secondary brain injury. It instead remains to be established whether hyperoxia plays a role, although a recent study comparing normoxia and mild hyperoxia in cardiac arrest patients did not demonstrate any difference in neurological outcome [4].

As a result of the risk of cerebral ischemia, hypocapnia should be avoided or used only briefly in emergency settings in the presence of intracranial hypertension, possibly in combination with brain tissue oxygen monitoring [5]. Hypercapnia, too, should be avoided, in this case because of the risk of vasodilation and increased ICP. Interestingly, in hypoxic ABI, moderate hypercapnia $(52 \mathrm{mmHg}$ ) was not associated with increased hospital mortality, as long as $\mathrm{pH}$ remained in the normal range [6].

\section{Ventilatory settings}

Maintaining normoxia and normocapnia in ABI patients being treated with LPV can be challenging. Most randomized controlled trials comparing MV strategies in ARDS have excluded patients with comorbid ABI. In patients suffering from ARDS, it is recommended to

\section{Springer}




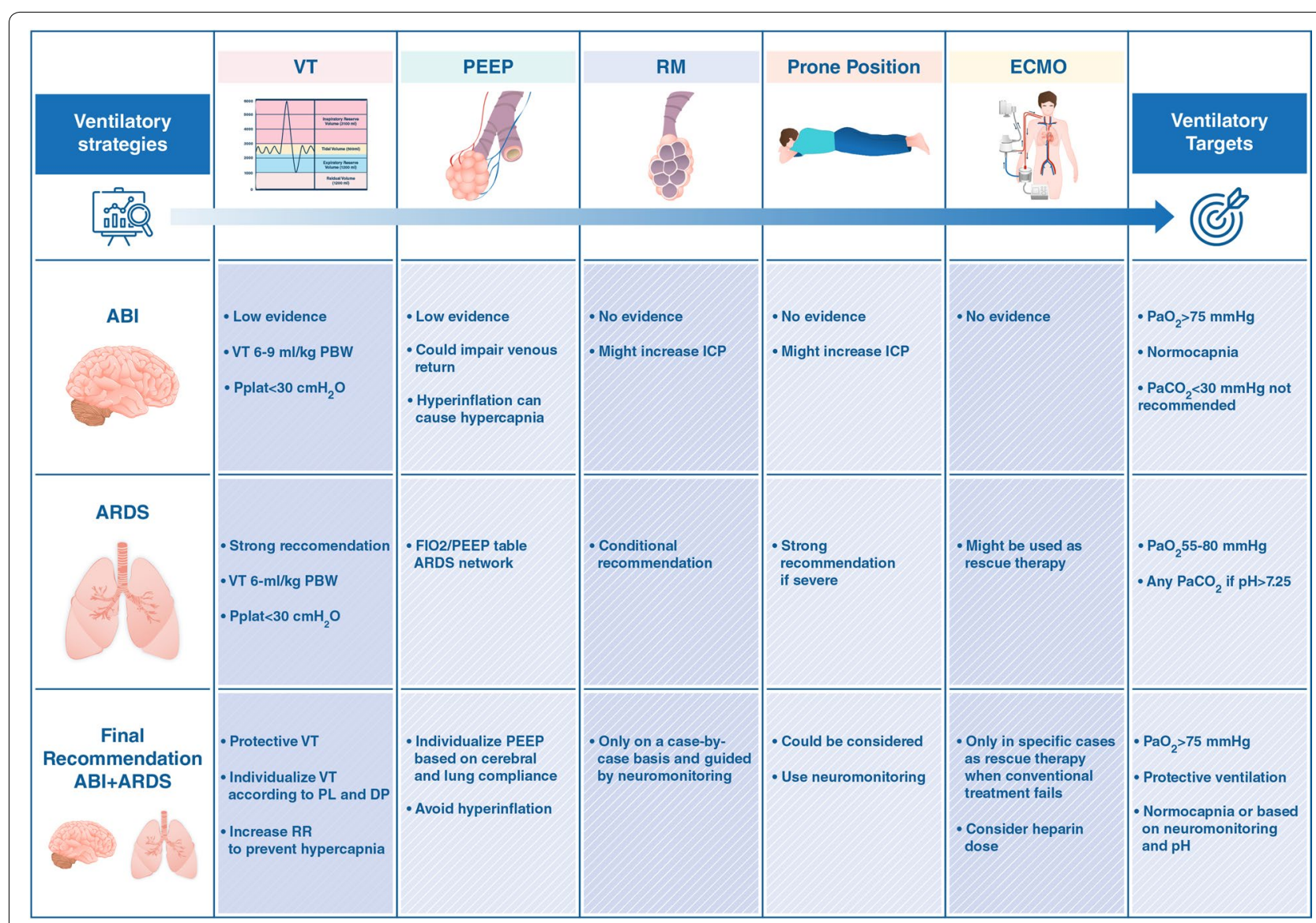

Fig. 1 Summary of ventilatory strategies and respiratory targets in patients with ABI and ARDS. In ABI, normoxia (>75 mmHg) should be the target as the role of hyperoxia in different neurological conditions has not yet been determined. Mild hypocapnia (30-35 mmHg) should be considered only if there is a risk of high ICP, whereas aggressive hypocapnia is not recommended except in situations of life-threatening brain herniation. Respiratory targets in ARDS include $\mathrm{PaO}_{2} 50-80 \mathrm{mmHg}$ and permissive hypercapnia. In patients presenting with both brain injury and respiratory failure it is therefore suggested to reach normoxia and $\mathrm{PaCO}_{2}$ levels according to multimodal neuromonitoring. If transpulmonary pressure measurement is not available, we suggest that $\mathrm{Vt}$ levels of up to $9 \mathrm{ml} / \mathrm{kg}$ might be acceptable in ABI patients with normal lungs [9], but recommend LPV with Vt $6 \mathrm{ml} / \mathrm{kg}$ in the presence of ARDS. RM and prone positioning might be used in ABI patients with severe ARDS under continuous neuromonitoring owing to an overall favorable risk-benefit ratio. Extracorporeal membrane oxygenation should be used only in selected life-threatening cases when conventional methods have failed. ABI acute brain injury, MV mechanical ventilation, $\mathrm{PaCO}_{2}$ arterial partial pressure of carbon dioxide, ICP intracranial pressure, PEEP positive end-expiratory pressure, Vt tidal volume, ARDS acute respiratory distress syndrome, VILI ventilator-induced lung injury, LPV lung protective ventilation, PBW predicted body weight, RM recruitment maneuvers

target a Vt of $6 \mathrm{ml} / \mathrm{kg}$ predicted body weight (PBW) [3] and keep the plateau pressure $<30 \mathrm{cmH}_{2} \mathrm{O}$ [3]. In nonARDS patients receiving invasive $\mathrm{MV}$, a large clinical trial comparing $4-6 \mathrm{ml} / \mathrm{kg}$ and $8-10 \mathrm{ml} / \mathrm{kg}$ PBW found no benefit from the lower Vt settings [7]. Notably, in patients with $\mathrm{ABI}, \mathrm{Vt}>9 \mathrm{ml} / \mathrm{kg} \mathrm{PBW}$ has been identified as a risk factor for ARDS [8]; other authors failed to confirm this association between Vt and ARDS, although they found high driving pressures to be associated with the development of ARDS [9]. Recently, a multifaceted ventilation strategy, consisting of $\mathrm{Vt} 7 \mathrm{ml} / \mathrm{kg}$, PEEP $6-8 \mathrm{mmHg}$, and early extubation, was found to reduce days of $\mathrm{MV}$ and mortality in ABI patients [10]. To date, however, no study has unequivocally shown that MV with high Vt per se increases ICP. Consequently, the optimal Vt value in ABI remains to be established. Outside dedicated trials, it is suggested to titrate Vt according to the size of the residual intact lung, using driving pressure and endinspiratory transpulmonary pressure settings to minimize overdistention.

To avoid hypercapnia as a possible consequence of lower Vt during MV, reducing apparatus dead space or increasing respiratory rate might be warranted. However, a higher respiratory rate is also associated with poor outcome in ABI patients [8], most likely mediated by increased mechanical power. 
PEEP is another component of LPV, with high PEEP levels $\left(\geq 15 \mathrm{cmH}_{2} \mathrm{O}\right)$ recommended only in cases of moderate to severe ARDS [3]. Improved arterial and brain tissue oxygenation have been described in ABI patients with ARDS submitted to progressively increasing PEEP levels [11]. In ABI patients, the effect of PEEP on ICP seems to depend mainly on PEEP-related hemodynamic effects and respiratory system compliance [12]. However, no distinction was made between lung and chest wall compliance.

Similarly, the use of recruitment maneuvers (RM) may potentially have a detrimental effect on ICP. In ABI patients with ARDS, lung recruitment has a transient positive effect on arterial oxygenation but can worsen cerebral hemodynamics and cerebral oxygenation during the procedure [13]. The Alveolar Recruitment for ARDS trial showed a worsening effect of the maximal recruitment strategy on patient survival [14]. However, there may be subgroups of patients that benefit from RM with improvement of oxygenation. We therefore suggest that RM may be performed under neuromonitoring, taking into account the benefit-to-risk ratio.

\section{Rescue therapies}

Prone positioning has been shown to improve outcome in severe ARDS patients [3], but no evidence exists in patients with elevated ICP, who have been consistently excluded from trials. A single-center controlled trial in comatose patients documented that short prone position sessions prevented worsening of respiratory failure, although an increase in ICP was observed [15].

However, since the detrimental effect of prone positioning on ICP remains to be clarified, prone positioning should still be considered in cases of refractory hypoxia.

There may be a role for veno-venous extracorporeal membrane oxygenation in severe ARDS, but as yet there is no evidence of its effect in ABI, probably because extracorporeal membrane oxygenation could potentially increase the risk of intracerebral hemorrhage due to anticoagulation.

In conclusion, no strong evidence exists regarding the use of LPV strategies in ABI patients. The traditional approach, namely that of combining intermediately sized Vt with low PEEP, is not contraindicated in patients with $\mathrm{ABI}$ and healthy lungs, while ABI patients with concurrent respiratory failure or ARDS can derive beneficial effects from LPV, which should therefore be taken into consideration in this population. Ventilatory targets and settings should be titrated individually under close neuromonitoring of brain physiology and lung mechanics, bearing in mind the old dictum, primum non nocere!

\begin{abstract}
Author details
${ }^{1}$ Department of Intensive Care Medicine, University Hospital of North Norway, Tromsö, Norway. ${ }^{2}$ Anaesthesia and Intensive Care, Policlinico San Martino, IRCCS for Oncology, Genoa, Italy. ${ }^{3}$ Service de Médecine Intensive-Réanimation, Hospices Civils de Lyon, Lyon, France. ${ }^{4}$ Université de Lyon, Lyon, France. ${ }^{5}$ INSERM 955, Créteil, France. ${ }^{6}$ Service de Médecine Intensive Réanimation, Grenoble, France. ${ }^{7}$ INSERM 1042, Grenoble, France.
\end{abstract}

Compliance with ethical standards

Ethical approval

An approval by an ethics committee was not applicable.

\section{Conflicts of interest}

Shirin Frisvold and Claude Guérin declare no conflicts of interest. Chiara Robba is a junior editor of Intensive Care Medicine.

\section{Publisher's Note}

Springer Nature remains neutral with regard to jurisdictional claims in published maps and institutional affiliations.

Received: 13 December 2018 Accepted: 2 February 2019

Published online: 18 February 2019

\section{References}

1. Pelosi P, Ferguson ND, Frutos-Vivar F, Anzueto A, Putensen C, Raymondos K, Apezteguia C, Desmery P, Hurtado J, Abroug F, Elizalde J, Tomicic V, Cakar N, Gonzalez M, Arabi Y, Moreno R, Esteban A (2011) Management and outcome of mechanically ventilated neurologic patients. Crit Care Med 39:1482-1492

2. Holland MC, Mackersie RC, Morabito D, Campbell AR, Kivett VA, Patel R, Erickson VR, Pittet JF (2003) The development of acute lung injury is associated with worse neurologic outcome in patients with severe traumatic brain injury. J Trauma 55:106-111

3. Fan E, Del Sorbo L, Goligher EC, Hodgson CL, Munshi L, Walkey AJ, Adhikari NKJ, Amato MBP, Branson R, Brower RG, Ferguson ND, Gajic O, Gattinoni L, Hess D, Mancebo J, Meade MO, McAuley DF, Pesenti A, Ranieri VM, Rubenfeld GD, Rubin E, Seckel M, Slutsky AS, Talmor D, Thompson BT, Wunsch H, Uleryk E, Brozek J, Brochard LJ (2017) An official American Thoracic Society/European Society of Intensive Care Medicine/Society of Critical Care Medicine clinical practice guideline: mechanical ventilation in adult patients with acute respiratory distress syndrome. Am J Respir Crit Care Med 195:1253-1263

4. Jakkula P, Reinikainen M, Hastbacka J, Loisa P, Tiainen M, Pettila V, Toppila J, Lahde M, Backlund M, Okkonen M, Bendel S, Birkelund T, Pulkkinen A, Heinonen J, Tikka T, Skrifvars MB (2018) Targeting two different levels of both arterial carbon dioxide and arterial oxygen after cardiac arrest and resuscitation: a randomised pilot trial. Intensive Care Med 44:2112-2121

5. van den Brink WA, van Santbrink H, Steyerberg EW, Avezaat CJ, Suazo JA, Hogesteeger C, Jansen WJ, Kloos LM, Vermeulen J, Maas Al (2000) Brain oxygen tension in severe head injury. Neurosurgery 46:868-876 (discussion 876-868)

6. Tiruvoipati R, Pilcher D, Botha J, Buscher H, Simister R, Bailey M (2018) Association of hypercapnia and hypercapnic acidosis with clinical outcomes in mechanically ventilated patients with cerebral injury. JAMA Neurol 75:818-826

7. Simonis FD, Serpa Neto A, Binnekade JM, Braber A, Bruin KCM, Determann RM, Goekoop GJ, Heidt J, Horn J, Innemee G, de Jonge E, Juffermans NP, Spronk PE, Steuten LM, Tuinman PR, de Wilde RBP, Vriends M, Gama de Abreu M, Pelosi P, Schultz MJ (2018) Effect of a low vs intermediate tidal volume strategy on ventilator-free days in intensive care unit patients without ARDS: a randomized clinical trial. JAMA 320:1872-1880

8. Mascia L, Zavala E, Bosma K, Pasero D, Decaroli D, Andrews P, Isnardi D, Davi A, Arguis MJ, Berardino M, Ducati A (2007) High tidal volume is associated with the development of acute lung injury after severe brain injury: an international observational study. Crit Care Med 35:1815-1820 
9. Tejerina E, Pelosi P, Muriel A, Penuelas O, Sutherasan Y, Frutos-Vivar F, Nin N, Davies AR, Rios F, Violi DA, Raymondos K, Hurtado J, Gonzalez M, Du B, Amin P, Maggiore SM, Thille AW, Soares MA, Jibaja M, Villagomez AJ, Kuiper MA, Koh Y, Moreno RP, Zeggwagh AA, Matamis D, Anzueto A, Ferguson ND, Esteban A (2017) Association between ventilatory settings and development of acute respiratory distress syndrome in mechanically ventilated patients due to brain injury. J Crit Care 38:341-345

10. Asehnoune K, Mrozek S, Perrigault PF, Seguin P, Dahyot-Fizelier C, Lasocki S, Pujol A, Martin M, Chabanne R, Muller L, Hanouz JL, Hammad E, Rozec B, Kerforne T, Ichai C, Cinotti R, Geeraerts T, Elaroussi D, Pelosi P, Jaber S, Dalichampt M, Feuillet F, Sebille V, Roquilly A (2017) A multi-faceted strategy to reduce ventilation-associated mortality in brain-injured patients. The BI-VILI project: a nationwide quality improvement project. Intensive Care Med 43:957-970

11. Nemer SN, Caldeira JB, Santos RG, Guimaraes BL, Garcia JM, Prado D, Silva RT, Azeredo LM, Faria ER, Souza PC (2015) Effects of positive end-expiratory pressure on brain tissue oxygen pressure of severe traumatic brain injury patients with acute respiratory distress syndrome: a pilot study. J Crit Care 30:1263-1266
12. Caricato A, Conti G, Della Corte F, Mancino A, Santilli F, Sandroni C, Proietti $\mathrm{R}$, Antonelli M (2005) Effects of PEEP on the intracranial system of patients with head injury and subarachnoid hemorrhage: the role of respiratory system compliance. J Trauma 58:571-576

13. Bein T, Kuhr LP, Bele S, Ploner F, Keyl C, Taeger K (2002) Lung recruitment maneuver in patients with cerebral injury: effects on intracranial pressure and cerebral metabolism. Intensive Care Med 28:554-558

14. Cavalcanti AB, Suzumura EA, Laranjeira LN, Paisani DM, Damiani LP, Guimaraes HP, Romano ER, Regenga MM, Taniguchi LNT, Teixeira C, Pinheiro de Oliveira R, Machado FR, Diaz-Quijano FA, Filho MSA, Maia IS, Caser EB, Filho WO, Borges MC, Martins PA, Matsui M, Ospina-Tascon GA, Giancursi TS, Giraldo-Ramirez ND, Vieira SRR, Assef M, Hasan MS, Szczeklik W, Rios F, Amato MBP, Berwanger O, Ribeiro de Carvalho CR (2017) Effect of lung recruitment and titrated positive end-expiratory pressure (PEEP) vs low peep on mortality in patients with acute respiratory distress syndrome: a randomized clinical trial. JAMA 318:1335-1345

15. Beuret P, Carton MJ, Nourdine K, Kaaki M, Tramoni G, Ducreux JC (2002) Prone position as prevention of lung injury in comatose patients: a prospective, randomized, controlled study. Intensive Care Med 28:564-569 